\title{
CURRÍCULO, CONHECIMENTO E DISCURSO: UMA EXPERIÊNCIA ESTÉTICA
}

CURRICULUM, KNOWLEDGE AND DISCOURSE: AN AESTHETICS EXPERIENCE

\author{
Guilherme Augusto Rezende Lemos \\ Universidade do Estado do Rio de Janeiro (UERJ), Rio de Janeiro, RJ, Brasil, guilhermealemos@yahoo.com.br
}

\section{RESUMO}

O presente artigo tenta pensar a Educação como estética ou como fruição, ou seja, ação de aproveitar ou usufruir de alguma oportunidade, uma utilização prazerosa de algo, um gozo e se concentra em três recortes, o primeiro, desenvolvendo um pouco o conceito de estética, não como filosofia da arte, mas como proposição do próprio homem como obra de arte; o segundo, obsevando um panorama da produção de sentidos em disputa que revela muito mais nosso modo de estar no mundo do que a contraposição de "argumentos verdadeiros"; por fim, aumentando a lente do microscópio, observaremos um mesmo fenômeno social suscitando visões opostas de mundo, para concluir o próprio discurso como fruição.

Palavras-chave Educação; currículo; estética.

\section{ABSTRACT}

This article to think of education as aesthetics or as enjoyment, that is, action to take or make use of any opportunity, a pleasant use of something a joy and focuses on three cuts, the first by developing a bit the concept of aesthetics not as philosophy of art, but as a proposition of man himself as a work of art; the second, observing an overview of the production of meaning in dispute that reveals much our way of being in the world than the opposition of "real arguments"; Finally, increasing the microscope, observe the same social phenomenon raising opposing worldviews, to complete the speech itself as enjoyment.

Keywords: Education; Curriculum; Aesthetics.

Artigo recebido para publicação em outubro de 2015

Artigo aceito para publicação em dezembro de 2015

\section{INTRODUÇÃO}

Se existe alguma coisa que una as muitas formas de se entender currículo, esta é a organização de experiências de aprendizagem que possibilitam o processo educativo (Lopes e Macedo, 2011). Os significantes experiência, aprendizagem e processo educativo configuram-se como aberturas para acordos discursivos acerca da produção de sentidos. A experiência é o lugar inventivo do processo educativo e da aprendizagem. A experiência é o local propício para a invenção da aprendizagem, onde aprender não necessariamente significa apreensão, compreensão ou assimilação, mas produção de sentidos; um rastro de subjetividade subssumida numa aparente atitude, numa intenção de ser, num discurso. 
O discurso é um conjunto de fatos linguísticos ligados entre si por regras sintáticas de construção. Foucault (2010) considera os fatos de discurso tal como os anglo-americanos: como jogos estratégicos de ação e reação, de dominação e de esquiva, como também de luta. Portanto, o sujeito do conhecimento é a cada instante fundado e refundado, através de um discurso tomado como um conjunto de estratégias que fazem parte das práticas sociais, o que contradiz a vigente compartimentação do conhecimento em disciplinas e, por conseguinte, a inadequação do magistério como formação a uma sociedade que, como afirma Stuart Hall (2006), já se configura sob a égide do sujeito descentrado. Talvez resida nessa inadequação o sentimento de crise que perpassa os meandros da Educação.

Assim sendo, proponho, tentativamente, pensar a Educação como estética, que não significa nada, que não quer dizer nada, mas que suscita a fruição. Ação, desenvolvimento ou efeito de fruir pressupõe a ação de aproveitar ou usufruir de alguma oportunidade, uma utilização prazerosa de algo, um gozo. Tal ação, desprovida dos limites do passado, que se sabe inventado, e do futuro obsoleto, já que o sentido inexiste, se realiza no espaço da criação e do suscitar a criação. Portanto a fruição atém-se a uma experiência estética.

O presente artigo se concentra em três recortes, o primeiro, desenvolvendo um pouco o conceito de estética, não como filosofia da arte, mas como proposição do próprio homem como obra de arte; 0 segundo, obsevando um panorama da produção de sentidos em disputa que revela muito mais nosso modo de estar no mundo do que a contraposição de "argumentos verdadeiros"; por fim, aumentando a lente do microscópio, observaremos um mesmo fenômeno social suscitando visões opostas de mundo, para concluir o próprio discurso como fruição.

\section{O CONCEITO DE ESTÉTICA}

A estética de Nietzsche, por exemplo, conforme Dias (2011), não é a tentativa de uma filosofia que possa entender a obra de arte, mas sim transformar o próprio homem em obra de arte, convencendo-o a abandonar a racionalidade iluminista e aderir a embriaguez e a ilusão consciente da existência 
estética, onde a criação e não mais a compreensão seja o dínamus dessa existência. Penso que no universo da interconexão e do sujeito traduzido a embriaguez dionisíaca seja uma possibilidade de nos sentirmos confortáveis num mundo ausente de sentidos onde a agência individual é verdadeiramente uma ilusão, sem que isso nos impeça de forjar formas, discursos, conversas sob a égide de Apolo.

Procuramos conhecimento, temos uma fundamental vontade de conhecimento, que governa e dirige as forças mais íntimas, e exige conceitos cada vez mais precisos. O que nos atrai é uma força que possui tudo quanto nos contradiz, tudo o que nos é antípoda. Para Foucault: o conhecimento em Nietzsche é fruto do confronto entre os próprios instintos (Hall, 2006). O conhecimento em Nietzsche não significa desvelamento, mas sim ação celebrativa da vida, por isso distancia-se da tríade: ciência (método), verdade (Deus, bem), sujeito (fundamento).

Luc Ferry (2008) encontra na crítica nietzschiana dos valores o modelo de todas as desconstruções, diz ele:

A primeira filosofia a literalmente aniquilar a noção de ideal enquanto tal e, então, preparar, sem querer, os espíritos para o advento dos principais efeitos intelectuais e morais da globalização foi a "genealogia" nietzschiana. Ela formou a matriz final de todas as vanguardas, de todas as filosofias da desconfiança, que teriam como principal tarefa a explosão em pedaços da dupla ilusão do sentido e da transcendência.

A ideia de criar é no sentido estético da obra de arte que, por sua vez, não tem origem nem fim e não quer dizer nada, apenas estar, fugazmente estar presente ao encontro. Esse ponto de vista embora sugestivo retira a importância da prescrição, pois qualquer proposição prévia não regulará a criação e o sentido catártico característico do aprender que não é privilégio de ninguém, mas do encontro onde espaço e tempo não necessariamente precisam coincidir. Nesse sentido, currículo, por exemplo, é qualquer coisa menos conteúdo disciplinar, está mais próximo dos fazeres pandisciplinares do que qualquer seccionamento possível. O currículo é encontro estético e, portanto, não-lugar, é modo de ver e estar no mundo. É uma experiência prezerosa de processo educativo pode coincidir com a violência e com o poder, como processos de siginificação em disputa.

\section{DA PRODUÇÃO DE SENTIDOS}


Um panorama bastante interessante acerca desses processos de significação em disputa pode ser observado em Lopes e Macedo (2010) quando analisam o pensamento curricular no Brasil no período que vai desde os anos 1920 até o ano 2000. Tal análise tem a preocupação, de um lado, com as influências políticas e teóricas sobre as noções de currículo, e consequentemente de conhecimento, que compuseram a história da educação no Brasil e, de outro lado, em elencar as diversas tendências do pensamento curricular para o então recém-nascido século XXI. Em nenhum momento a tônica das análises incide sobre uma possível cronologia evolutiva, mas sobre interpretações de contextos históricos.

O longo período que vai de 1920 a 1980 é classificado pelas autoras, e também por Moreira e Macedo (1999), como de 'transferência instrumental de teorizações americanas', consequente da condição de refém em que a América Latina, incluindo o Brasil, se encontrava na sua trajetória desenvolvimentista. Tais teorias em sua maioria de caráter funcionalista iniciavam um processo de disciplinamento do brasileiro rumo ao pensamento técnico e particularizado. Interessante perceber, já nesse momento, uma dissenção entre conhecimento e processo identitário. O pensamento técnico e setorizado não pretende, em princípio, nenhuma intervenção na identidade nacional ou na subjetividade, mas instrumentalizar o indivíduo com o intuito de aumentar a sua performance para 0 mercado. Desse modo discreto o "espírito" globalizado tenta se imiscuir nas almas sem que estas se apercebam, incentiva a individualidade ao mesmo tempo em que delimita o campo onde devem agir as suas individualidades.

É imperceptível aos indivíduos de então as marcas que vão sendo aos poucos esculpidas em suas (in)consciências, até porque tais marcas não são intencionais nesse sentido ou pelo menos não têm um autor claramente definido. A partir dos anos 50, ainda do século XX, a ideia de desenvolvimento tecnológico, inequivocamente de cunho capitalista, dirigia-se ao sincero desejo de crescimento das sociedades calcado nos princípios da democracia liberal e dos direitos do homem, estes sim, defendidos, pelo menos na fala, pela esquerda e que paradoxalmente se encontram no fundo do individualismo radical dos tempos atuais. 
A erradicação da pobreza surge como argumento e meta incontestável da democracia liberal e dos direitos do homem, o que os Estados Unidos da América podiam demonstrar de forma cabal e o faziam associando a liberdade de se "poder ser o que se é", enfatizando assim a máxima liberal, onde a prosperidade individual abre frentes de trabalho e, por conseguinte, promove a de outrém. $\mathrm{O}$ alvo em princípio não era a transformação das culturas locais, mas operar os ajustes necessários a um modo de produzir bens de consumo universal com garantias de comercialização e, consequentemente, o alargamento da capacidade de carrear recursos e propiciar riqueza: "continue sendo o que você é só que comercialmente mais eficaz e com um pouco mais de conforto. Que mal há nisso?" Pode-se perguntar à guisa de ironia. Obviamente que por trás disso havia o interesse na exportação de produtos e tecnologias, como maquinário, automotivos e, principalmente, a linha de produção e o modo de produzir.

Além disso, a indústria cinematográfica, calcada exatamente na ideia de indústria, toma a si a tarefa de inventar, como produto, o american way of life. $\mathrm{O}$ fomento americano a regimes autoritários surge da conjugação de interesses de ampliação de mercado tanto internos como externos. Aos olhos do "americano empreendedor" apenas mais uma forma de vender, de lucrar. Vale lembrar que a dissolução do governo militar no Brasil, por exemplo, só alcançou amplo apoio da população quando esta se viu garantida no seu direito a democracia liberal e ao respeito aos direitos do homem, está aí a Constituição de 1988 como prova inconteste. Segundo Lipovetsky (Lipovetsky e Charles, 2011), os direitos do homem são a fonte segura e inequívoca do individualismo e do hedonismo dos tempos atuais e, por conseguinte, a lógica de livre mercado e o sistema da moda.

Portanto é no dínamus da cultura, ao modo de um imenso "inconsciente" coletivo, que as mudanças vão sendo tramadas sem que os indivíduos se apercebam. A ideia de lucro, as lutas por direito e liberdade individuais, o desenvolvimento da comunicabilidade, aumentando as possibilidades de troca, a busca pela eficácia, as utopias de uma vida boa, a vontade de poder e saber e o desejo de não ser um rosto na multidão, posto que indivíduo; tudo misturado no mesmo cadinho resulta na igualdade da intenção: individuar-se, e na diferença da condução: individuar-se. 


\section{UM FATO, DUAS VISÕES}

Apesar das individuações, conviver é preciso, nesse sentido "um debate atinge a maturidade quando as posições mais extremas deixam de se opor frontalmente para tentar identificar o que há de convincente na argumentação contrária", é com essas palavras que Pierre-Henri Tavoillot inicia seu prefácio ao registro escrito de um debate ocorrido no Collège International de Philosophie, Paris, organizado numa série de sessões, entre novembro de 2008 e abril de 2009, sobre o tema cultura e mundialização. De cada lado da arena Gilles Lipovetsky e Hervé Juvin (2011).

Como havíamos dito no ínico do texto, o currículo é encontro estético e, portanto, não-lugar, é modo de ver e estar no mundo. Nesse sentido, o debate entre Lipovetsky e Juvin é revelador quando um mesmo fenômeno social, a mundialização, suscita duas visões diametralmente divergentes. Tal como observamos anteriormente, quando das produções de sentido em disputa, agora observaremos os rudimentos dessa produção, para conclucir que a nossa realidade nos proporciona fruições múltiplas que se fenomenizam como possibilidades de verdades e, por conseguinte, de conhecimento.

Tratam-se de argumentações possantes, bem urdidas, por homens que observam a mundialização há muito e com olhar bastante acurado, parece que nada lhes escapa. Na superfície das análises percebese um otimismo, nada ingênuo, por parte de Lipovetsky, e um pessimismo desconcertante em Juvin. De ambos os lados a constatação de que a lógica do mercado e o sistema da moda não são mais um algo fora de nós, tornaram-se-nos intrínsecos e implícitos. Somos todos mercado e moda e por mais que aparentemente pipoquem aqui e ali movimentos de resistência, a própria lógica dos movimentos os reduzem a mercado e moda e isso não é mais um privilégio do Ocidente.

"Inegavelmente a cultura-mundo é inseparável de um trabalho de uniformização planetária: sobre este ponto nós estamos de acordo" (Lipovetsky e Juvin, 2011: 195), comenta Lipovetsky em relação a Juvin. No entanto, o primeiro, defende que a cultura individualista não se constitui como uma superestrutura nem muito menos como um simples dobrar-se a "economia-mundo". Para Lipovetsky essa cultura não é em si mesma um todo homogêneo, muito ao contrário se constitui de lógicas diversas e 
heterogêneas que ao se cruzarem tanto se reforçam como se chocam e se conflituam. Do mesmo modo que o Globo se movimenta rumo a uma uniformização do modo de viver este mesmo "modo de viver" produz comportamentos individuais singulares e heterogênios exatamente pelo "recuo dos enquadramentos coletivos". Diz ele:

"O indivíduo não se funde numa massa conforme e homogênea: constrói-se ao pedir emprestado os modos e os modelos comuns do consumo segundo 'arranjos' singulares. [...] a diversidade no espaço foi subsituída pela diversidade no tempo [...] Não somos ameaçados pela monotonia, mas pelo hiper, pelo excesso, pelo pletórico" (p.196).

Esse mesmo ponto de vista que Lipovetsky encara de modo otimista, dizendo que a uniformização do modo de vida não extermina com a criatividade humana, é o mesmo que leva Juvin a pensar que o agravamento das vontades individuais, para ele sempre insatisfeitas, é o que produzirá muito em breve um sistema autofágico de ódio e destruição:

\footnotetext{
Nove mil milhões de indivíduos semelhantes, persuadidos da sua individualidade, incitados a fazer valer os seus direitos, convencidos de que se tornaram livres ao fugir de todas as determinações, ao recusar as suas origens, seduzidos pelo seu novo ser econômico que acaba de confundir neles o produtor e o consumidor na mesma utilidade global. (p.190).
}

$\mathrm{Na}$ verdade a tensão entre Lipovestsky e Juvin recai sobre a concepção que cada um tem do que seja cultura. Para Juvin "Cultura e mundialização opõem-se, como gratuidade e comércio, como artista e comerciante, como dádiva e mercado" (p.189). Para Juvin "havia culturas. Ao longe, a curiosidade, a irredutível distância" (p.119). A geografia e a história advindas da lida com os complexos aspectos climáticos e produtivos determinavam o modo de ser dos homens e as singularidades dos agrupamentos, esses mesmos homens encontravam no sagrado a fonte inesgotável de sua produção simbólica. Por isso Juvin vê na cultura mundializada uma imensa crise que consiste na substituição do singular pelo particular, por conta exatamente das quebras das barreiras geográficas, pelo desprezo ao sagrado e pela "mesmificação" da existência. "O elogio da mobilidade, o cosmopolitismo erigido em princípio moral, o interesse individual sacralizado pelos direitos do indivíduo" (p.119), tudo e todos convocados à sua utilidade. Tudo isso agravado pela mediatização que dá a todos a ideia de que tudo é possível, de que tudo no mundo está à sua disposição. 
Para Juvin o crescimento da economia a retirar, como nunca na história, as pessoas da pobreza é que dá à noção de crescimento o estatos de critério de verdade e de condição de poder. A cultura torna-se assim mercado da cultura, aos seus olhos, "a cultura era o modo de voltar atrás, de julgar e de dizer não" ao passo que a cultura-mundo "dissolve as questões na ação, [...] resolve-se numa imensa aquiescência ao crescimento, ao mercado e as suas obras" (p.125). Tudo isso transforma a relação com o estrangeiro (etnia) em relação com o outro (indivíduo). A redução da cultura à economia gera um sentido de competitividade entre os homens que, ao contrário da propalada humanidade apaziguada, Juvin enxerga na separação do indivíduo do todo coletivo uma terrível fonte de conflito e ódio. É conduzindo cada indivíduo à "abstração de sujeito de direito" (p.139) que a política liberal despe o homem de sua cultura singular construída a partir de um passado, de uma origem, de uma relação com a terra e com a história.

\footnotetext{
A educação, o ensino, a formação são os teatros deste drama; a desculturação caminha lado a lado com a socialização, esta aposta na conformidade das crianças e dos jovens que exclui o controle da língua - com que direito se pode pedir que as crianças da diversidade falem francês? (...) Não pode haver educação sem discriminação e sem seleção e só uma sociedade que sabe o que se deve e conhece o seu encerramento pode legitimar as suas instâncias de educação, sem ser perfurada pela frase "para que é que isto serve?". Porque isto serve, em primeiro lugar, para se tornar francês, europeu, civilizado, na diferença, na exigência, mesmo na confrontação com os que serão de um outro mundo - de uma outra cultura, que não tem nada a fazer deste mundo, destas instâncias que não têm, simplesmente, nada a fazer aqui. (pp 138-139).
}

A propósito dessa fala de Juvin, a despeito de concordâncias ou discordâncias, só quem anda pela Europa tem a dimensão do que seja o problema da imigração nesse continente. Não se trata de uma confrontação rasa entre complacência e xenofobia, o fenômeno tem proporções inimagináveis para quem não o viu de perto. A Europa é uma imensa torre de babel a ser invadida a cada dia por hordas imensas de imigrantes em busca dos mais diversos objetivos incluindo-se aí o exercício, de ambas as partes, do ususfruto parasitário, da espolição, do ódio e da vingança justificados na história do eurocentrismo.

Segundo Juvin:

\footnotetext{
O assunto é atual. A crise na qual o sistema de mercado nos faz entrar é uma crise da cultura, uma vez que ela é uma crise da relação com o real, do julgamento e da inteligibilidade do mundo. Ela é também uma crise das culturas particulares, daquelas que fazem a vida, que dizem como comer, deitar, amar, transmitir, do plural apreendido pelo singular e pela sua pretensão de ser a cultura de todos. Face a esta crise moral e social, uma só atitude é impossível: negar a importância das transformações que esvaziam de sentido a
} 
palavra cultura tal como foi pronunciada e debatida desde acerca de dois séculos e que fazem da cultura outra coisa, uma outra realidade e uma outra palavra. (p.116)

Na pena de Lipovetsky a palavra cultura assume outra conotação. Enquanto Juvin é pessimista porque olha a munidalização da perspectiva dessa cultura civilizatória em crise, Lipovetsky mergulha naquilo que chama de cultura de "terceiro tipo":

\footnotetext{
A globalização é também uma cultura. Estamos, assim, no momento em que se coloca e em que cresce demesuradamente uma cultura de "terceiro tipo", uma espécie de hipercultura transnacional que propus chamar, com Jean Serroy, cultura-mundo. (p.16)

Já não estamos na ordem nobre da cultura definida como via do espírito, estamos no "capitalismo cultural" em que as indústrias da cultura e da comunicação se impõem como instrumentos de crescimento e motores da economia. (p.16)

A cultura não é somente uma super-estrutura sublime de signos, ela remodela o universo material da produção e do comércio. Em contexto idêntico, as marcas, os objetos, a moda, o turismo, o habitat, a publicidade, tudo tende a tomar um matiz cultural, estético e semiótico. Quando a economia se torna cultura e quando o cultural penetra no comércio, chega o momento da cultura-mundo. (p.17).
}

Por isso Lipovetsky é otimista, cruzou a fronteira da crise e já analisa a cultura em sua nova configuração, mas é otimista porque apesar da inegável uniformização do mundo pelo critério do mercado, percebe vivo o exercíco da criatividade e da produção simbólica, constata que não nos tornamos robôs ou seres lobotomizados, continuamos singulares e criativos, ainda mais singulares e criativos, ao exato contrário do que pensa Juvin. Para o primeiro trata-se tanto da "mercantilização da cultura quanto da culturalização do mercado" (p.49), o que significa não o fim da produção simbólica, mas outro tipo de produção simbólica; cinco grandes polos constituem esse novo cenário da produção simbólica: o consumo, o mercado, a técnica (cientificizada), a mídia e o indivíduo.

Lipovetsky não nega a persistência de algumas "antinomias estruturais" (p.17), mas considera-as menos explicativas para as crises do capitalismo do que a inserção do "hiper", do excesso, nos diferentes aspectos da vida coletiva com sua "overdose publicitária e comunicativa". Enquanto a cultura popular e a "cultura cultivada" persistem numa oposição irremediável, a cultura-mundo "desdobra-se no reino da universalidade cosmopolita, da mudança perpétua, do pletórico" (p.18). Ao contrário da noção de cultura como organizadora da vida, a cultura-mundo desorganiza ininterruptamente o ser-no-mundo, a consciência e a existência. Explode e implode todos os sitemas de referências, fruto do alívio de enquadramentos coletivos e simbólicos. Paradoxalmente, isso em nada 
significa o triunfo da democracia liberal ou a uniformização da espécie, "a individualização acelera a globalização e esta intensifica a individualização" (p.66). Trata-se do que James Clifford conceitua como "glocalização" (Apud. in Lipovetsky e Juvin, 2011) onde os símbolos propalados pela globalização são reinterpretados e adaptados à cultura local. A imersão dos membros de uma facção fundamentalista no mundo da web, não os faz menos fundamentistas, ao mesmo tempo que introduz novos hábitos no seu interior serve-lhes de ferramenta aos seus princípios e ações, mas também reconfigura a sua visão de mundo, não há como fugir ao paradoxo.

Embora o cosmopolitismo tenha suas raízes fincadas na história do Ocidente, o que hoje se pratica não coincide com o humanista ou o idealista, também não se trata de um internacionalismo proletário e revolucionário,

Mas de um universalismo concreto e social, complexo e multidimensional, feito de realidades estruturais que se cruzam, que interagem, que se contrariam. O mercado, o consumismo, a tecnociência, a individualização, as indústrias culturais e a comunicação constituem os princípios organizadores de fundo. (p.20).

Lipovetsky não acredita na uniformização completa do Globo, mas também não pode deixar de constatar que ele se encontra transpassado por 'dispositivos criadores de uma cultura transnacional multipolar'. A mundialização não é mais uma possibilidade a ser redirecionada ela é uma 'realidade objetiva na história', onde não nos cabe mais o contra ou a favor, resta-nos a tentiva de entendimento, o sentimento de crise concentra-se no embate entre o assim viver como se não o fosse. Para o autor "a compressão do tempo e do espaço", reconhecendo a fórmula de David Harvey (p.21), onde o espaço é reduzido e o tempo acelerado por conta do "cyber-tempo global", não dissolve as distâncias culturais e nisso consiste a interessante percepção do paradoxo atual. A mesma lógica do mercado e sistema da moda que uniformiza são os mesmos ingredientes que forjam as diferenças. 0 individuar-se não necessariamente incide sobre a pessoa, mas também sobre um conjunto de pessoas, a mesma lógica que faz com que pareçamos uniformes é a mesma que exalta e estimula a diferença, seja da pessoa, seja do agrupamento. Por outro lado, a luta pelo reconhecimento ou pela visibilidade de certa indentidade étnica, por exemplo, não invalida a ação de cada indivíduo dentro do grupo no sentido de uma identidade própria. 
O cosmopolitismo da cultura-mundo não é apenas aquele de aeroporto e suas grifes de luxo, mas também o que faz circular e comungar vírus, crise econômica, terrorismo, desastres ecológicos, festivais, olimpiadas, celebridades de toda sorte. "Já ninguém pode escapar: passamos de um cosmopolitismo livre e voluntário a um cosmopolitismo inelutável finalizado com o objetivo de uma sobrevivência econômica" (p.30). Já não se trata de escolher ser cidadão do mundo, somos constrangidos a isso, nem que seja pelo noticiário do rádio de pilha.

\section{CONCLUSÃO}

Se o "cosmopolitismo é inelutável", cabe proteger a cultura-mundo dela mesma, o que significa impedir a hipertrofia financeira e a especulação superlativa, sem com isso querer governar o mundo num rumo unidirecional. Esse é um trabalho que deve ser distribuído por todos e a educação tem um papel fundamental nisso, a começar por restituir ao professorado o poder de curriculizar (currere, cf. Pinar, 2007), permitindo-lhe refletir sobre o conhecimento que ministram em particular e sobre o mundo em que vivem no coletivo.

A interconexão e a interatividade nos conduzem de forma irreversível para a constatação da impossibilidade de encontrarmos em nós mesmos um ponto que nos una. No universo da interconexão tudo o que se percebe é diferença, tudo que ressalta é diferença, o que aponta para alguns problemas muito próprios de nossa era de "identidades líquidas": de um lado, a apressada e reconfortante busca por fundamentalismos sejam eles políticos, étnicos ou religiosos, como forma de assegurar uma "identidade" que dê sentido a existência; de outro, o culto da diferença como sendo o ilusório ambiente da liberdade de escolha como autodeterminação.

Viver na diferença requer conflito, debate, embate, mas acima de tudo compromissos éticos que assegurem a todos a expressão, com um agravante, a certeza de que tudo é provisório e fluido e é aí que se encontra o problema e a importância do debate sobre o currículo em nossa cultura escolar: como pensar/praticar um currículo que seja "fruição"? Como pensar/praticar uma educação na diferença que 
exercite o comprometimento ético, sabendo-o fluido? Como pensar/praticar uma educação que não tenha a intenção, previamente fracassada, de produzir identidades, mas que fomente a identificação como exercício de escolha, seja ela pessoal ou coletiva? Parece que a noção de currículo se afasta cada vez mais dos ditos "conteúdos" para instalar-se nas práticas da arte de conviver, investindo a escola de uma importância que talvez nunca tenha tido, não como a instância do ensino, mas sim como da possibilidade privilegiada da convivência de modo não virtual e, por que não, também virtual.

Conviver na diferença é uma arte que precisa ser aprendida na prática, no confronto diário, buscando a cada dia uma solução nova, pois não há uma lógica ou uma técnica que a possibilite. Entendendo-se o confronto como matéria intrínseca e não como algo a ser evitado a qualquer preço, o compromisso ético é sempre fruto de confronto e, por isso, precisa ser constantemente revisto. Isso significa descartar a ciência e o conhecimento? Em absoluto, mas significa colocá-los no seu lugar de ferramentas e não de fundamento ou objetivo. Nada o "é" porque se conhece, as coisas "são" porque assim se conformaram circunstacialmente, e o são na condição de passadiço.

A conformação não é a determinação definida por um grupo ou pessoa, mas o resultado de um conjunto de forças só perceptível como interpretação do já ocorrido na faixa mediana da cultura. Portanto, um pensamento hegemônico, por exemplo, é uma construção discursiva de uma hegemonia apenas teórica, já que é constantemente reconfigurada pela faixa mediana da cultura que é o local do confronto inconsciente. Como a dita hegemonia é apenas um processo de significação como tantos outros, é ressignificada a cada novo discurso que sobre ela se debruça e, portanto, não pode manter-se estática fundamentando uma ação propriamente dita.

É importante entender que o próprio confronto no interior da cultura, assim como seu resultado sempre provisório, já que fruto de um confronto ininterrupto, é absolutamente inconsciente e não se constitui como agência. Paul Veyne (2009), fazendo uma decupagem do pensamento de Foucault a respeito, nos diz o seguinte:

Usando e abusando de uma analogia freudiana, Foucault diz ter "tentado libertar um domínio autônomo que seria o do inconsciente do saber", "reencontrar na história da ciência, dos conhecimentos e do saber humano algo que seria como que o seu inconsciente". "A consciência nunca está presente numa tal descrição" dos 
discursos; os discursos "permanecem invisíveis", são "o inconsciente, não do sujeito falante, mas da coisa dita" (sou eu quem sublinha), "um inconsciente positivo do saber, um nível que escapa à consciência" dos agentes, que eles utilizam "sem que dele tivessem consciência".

O termo "inconsciente" não é senão uma metonímia: só existe inconsciente, freudiano ou outro, nos nossos cérebros; em vez de "inconsciente", leiam "implícito". (p.22).

Veyne, baseado em Foucault, classifica como discurso exatamente "aquilo que não é dito e que permanece implícito" (p.23). Portanto, embora o discurso se configure como um quadro formal ele não coincide literalmente com o objeto sobre o qual se refere, isto é, a verdade proferida pelo discurso não corresponde com o real. Para Foucault, na visão de Veyne, discurso "é a descrição mais precisa, a mais cerrada de uma formação histórica na sua nudez, é o por em dia da sua última diferença individual” (p.12). Desse modo, discurso é a singularidade implícita que movimenta a racionalidade de uma época, racionalidade essa que, paradoxalmente, o recobre como uma carapaça de "verdade" ou de "hegemonia" que a todo momento é arguida por uma espécie de ato falho proveniente do "inconsciente" do saber: o próprio discurso ou a realização da fruição.

\section{REFERÊNCIAS}

DIAS, Rosa Maria. Nietzsche, a vida como obra de arte. Rio de Janeiro: Civilização Brasileira, 2011.

FERRY, Luc. Famílias amo vocês: política e vida privada na era da globalização. Tradução de Jorge Bastos. Rio de Janeiro: Objetiva, 2008.

FOUCAULT, Michel. A hermenêutica do sujeito: curso dado no Collège de France (1981-1982). Edição estabelecida sob a direção de François Ewald e Alessandro Fontana, por Frédéric Gros. Tradução: Márcio Alves da Fonseca, Salma Annus Muchail. 3 ed. São Paulo: Editora WMF Martins Fontes, 2010.Stuart Hall (2006)

LIPOVETSKY, Gilles \& CHARLES, Sébastien. Os tempos hipermodernos. Tradução: Luís Filipe Sarmento. Lisboa: Edições $70,2011$.

; JUVIN, Hervé. O ocidente mundializado: controvérsia sobre a cultura mundializada. Tradução: Luís filipe Sarmento. Lisboa: Edições 70, 2011.

LOPES, Alice Casimiro \& MACEDO, Elizabeth Fernandes de. CURRÍCULO: DEBATES CONTEMPORÂNEOS. $3^{\text {a }}$ ed. São Paulo: Cortez, 2010.

; MACEDO, Elizabeth. Teorias de Currículo. São Paulo: Cortez, 2011. Apoio: Faperj.

MOREIRA, Antonio Flávio Barbosa \& MACEDO, Elizabeth Fernandes de. Faz sentido ainda o conceito de transferência educacional?. In: CURRÍCULO: POLÍTICAS E PRÁTICAS. Org. Antonio Flávio Barbosa Moreira. 11ª ed. Campinas, SP: Papirus, 1999. pp. 11-28. 
PINAR, William F. O que é a Teoria do Currículo?. Tradução da Aba Paula Barros e Sandra Pinto. Porto: Porto Editora, 2007.

VEYNE, Paul. Foucault: o pensamento, a pessoa. Tradução: Luís Lima. Lisboa: Texto e Grafia, 2009. 